\title{
1 Inbreeding depression from selfing and mating between relatives in the Neotropical tree Cariniana legalis Mart.
}

\section{Kuntze}

3 Evandro Vagner Tambarussi ${ }^{1,5}$, David Boshier ${ }^{2}$, Roland Vencovsky ${ }^{3}$, Miguel Luiz Menezes Freitas ${ }^{4}$ and Alexandre

4 Magno Sebbenn ${ }^{4}$

5

$6 \quad{ }^{1}$ Universidade Estadual do Centro-Oeste, PR 153, Km 7, Irati, PR, 84500-000, Brazil1,

$7 \quad 2$ University of Oxford, Department of Plant Sciences, South Parks Road, Oxford, OX1 3RB, UK,

8 3 $\quad{ }^{3}$ Escola Superior de Agricultura “Luiz de Queiroz” Universidade de São Paulo, Av. Pádua Dias, 11, Caixa Postal 9,

9 Piracicaba, SP, 13418-900, Brazil,

$10{ }^{4}$ Instituto Florestal de São Paulo, CP 1322, São Paulo, SP, 01059-970, Brasil.

$11 \quad{ }^{5}$ Corresponding author: tambarussi@gmail.com (Telephone: +55 4234213087 and fax: + 554234213067 )

Keywords: conservation genetics; inbreeding; mating among relatives; microsatellite loci; tropical tree species. 
Abstract

Selfing or mating between related individuals in self-compatible hermaphroditic tree species may lead to inbreeding depression (ID) due to homozygosis in recessive, identical by descent alleles. In general, studies of ID in tree species have been based on comparisons of selfed individuals (produced by controlled pollination) with outcrossed individuals for quantitative traits in progeny tests. However, this approach requires a long time to quantify the extent of ID. Thus, we used an approach based on genetic markers to estimate coancestry coefficients between assigned parents from paternity analysis in two populations of the Neotropical tree Cariniana legalis. Using this method, we were able to determine which seedlings in a nursery trial originated from; i) outcrossing between un-related trees, ii) mating between related trees and iii) selfing. We detected a low selfing rate $(<10 \%)$, but a substantial quantity of seedlings from mating between related parents (minimum of 35.7\%). In general, the outcrossed seedlings from unrelated parents exhibited significantly greater genetic diversity than those resulting from selfing and mating among relatives. The extent of ID varied among traits and populations. Outcrossed seedlings originating from unrelated trees generally showed greater survival than seedlings originating from selfing and related parents. Inbreeding depression was greater in the selfed seedlings than in those from mating among related parents. The results are discussed in terms of implications for genetic conservation, breeding and environmental restoration using the species. 


\section{Introduction}

Tree populations across much of the world have suffered fragmentation or intensive logging, with associated decreases in population size and physical isolation. A consequence may be increased rates of selfing and mating between related trees, with a higher incidence of inbred individuals in succeeding generations (Lowe et al. 2005; Chaves et al. 2011; Manoel et al. 2012; Ismail et al. 2012; Rymer et al. 2015; Tambarussi et al. 2015). Inbreeding in plants may lead to inbreeding depression (ID), where homozygosity increases in identical by descent (IBD) alleles produce individuals with reduced mean phenotypic values for reproductive, physiological efficiency and adaptive traits, compared to those originating from outcrossing among unrelated individuals (Charlesworth and Charlesworth 1987; Ritland 1996; Falconer and Mackay 1997; Byers and Waller 1999; Winn et al. 2011). As ID may decrease survival, growth and reproductive fertility, the possibility and extent of ID in tree populations is of direct practical importance for genetic conservation, breeding and environmental restoration, in particular for small isolated (Lowe et al. 2005). Use of inbred seeds should be avoided in ex situ conservation due to the decrease in effective population size, while higher mortality and reduced growth increase the costs of conservation and reforestation.

In natural populations of insect-pollinated tree species, inbreeding can result from pollinator visitation of flowers on the same tree (selfing) or on neighbouring trees (mating among relatives) that show intra-population spatial genetic structure (SGS) generally resulting from limited seed dispersal (e.g. Bittencourt and Sebbenn 2007; Dick et al. 2008). Selfing produces at least 50\% inbreeding $\left(F_{s}=0.5\left(1+F_{m}\right)\right.$, where $F_{m}$ is the inbreeding coefficient of the mother, while mating between two related individuals produces inbreeding $\left(F_{r}\right)$ of similar strength as the coancestry ( $\theta$ ) among the related parents, $F_{r}=\theta$ (Lindgren et al. 1997). Thus, inbreeding due to mating among related trees is expected to be less deleterious than that due to selfing, because mating between full-sibs ( $\theta=0.25)$ or an offspring and one parent ( $\theta=0.25$ ) will produce a maximum of $25 \%$ inbreeding.

Inbreeding depression can be expressed at different life stages of an organism, while also varying across populations, individuals and traits (Griffin and Cotterill 1988; Wu et al. 1998; Koelewijn et al. 1999). In the first case, the genes responsible for deleterious effects at different stages of life are not necessarily the same. Variation in ID among individual plants and populations can be expected as they differ in the numbers and frequency of deleterious alleles they carry, with mutations differentially accumulated across populations and progeny (Koelewijn et al. 1999). Many studies of coniferous and deciduous tree species comparing selfed with outcrossed progeny in provenance and progeny tests, have revealed ID for flowering, seed production and germination, survival, and growth traits, as well as increases in phenotypic variation among progeny arrays (e.g. Griffin and Cotterill 1988; Sorensen 1997; Wu et al. 1998; Koelewijn et al. 1999; Chaves et al. 2011). 
In the present study, we used a different approach to estimate ID in a large tree of the Atlantic rain forest, i.e.,

Cariniana legalis L (Lecythidaceae), using seven codominant nuclear microsatellite loci, paternity analysis and estimates of pairwise coancestry between seed trees and pollen donors assigned by paternity analysis. Paternity analysis permits the detection of selfed seeds and the father of outcrossed seeds where the seed tree is known. Outcrossed seeds are not inbred if they result from mating between unrelated parents and inbred if from related parents. The degree of relatedness among seed trees and assigned pollen donors (seed parents) of sampled seeds can be inferred from pairwise coancestry coefficient estimates $(\theta)$. Seed parents can be non-relatives $(\theta \leq 0)$ or relatives $(\theta>0)$. Thus, the combination of paternity analysis and estimates of the pairwise coancestry coefficient between seed parents permits estimation of the rate of mating among relatives. If genotyped open-pollinated seeds used in the paternity analysis are established in a progeny test, quantitative and qualitative traits can be measured. Thus, each plant can be grouped as originating from selfing, mating among related individuals or outcrossing among non-relatives, and the means of traits can be estimated for each of these three groups. Consequently, ID from selfing and mating among relatives can be estimated for a phenotypic trait, as the relative performance of inbred individuals in relation to the performance of outcrossed individuals from unrelated parents. Using this approach, we investigated the extent of ID due to selfing and mating among relatives, for survival, growth in height $(\mathrm{H})$ and root-collar diameter (RCD) in 8 month old seedlings originating from seed collected in three fragmented C. legalis populations and established in a nursery provenance and progeny test. We addressed the following questions: i) Which of the study traits was most strongly affected by ID? ii) Are there differences in the levels of ID between populations? iii) What are the differences in ID among seedlings that originated from selfing compared to mating among relatives? iv) Are there differences in the levels of genetic diversity between seedlings produced by selfing, mating among relatives and outcrossing among non-relatives? v) Based on random samples of seedlings from these populations, what is the expected level of ID in the offspring generation?

\section{Material and Methods}

\section{The studied species}

Cariniana legalis Mart. O. Kuntze (Lecythidaceae) is an endemic, upper canopy tree of the Atlantic forest that occurs between latitudes 8 and $23^{\circ} \mathrm{S}$, generally at low density ( $<1$ tree/ha), reaching $60 \mathrm{~m}$ in height and $4 \mathrm{~m}$ in diameter at breast height (Carvalho, 2003). The species is semi-heliophytic and evergreen, with hermaphroditic flowers pollinated by bees of the genera Melipona and Trigona (Prance and Mori 1979), and seed dispersed by gravity and wind (Carvalho 2003). The wood is light and used in civil construction and furniture. The species is considered endangered (Sebbenn et al. 2000), and a better understanding of ID will provide useful information for effective in and ex situ conservation measures. 


\section{Study sites and sampling}

The study was performed using open-pollinated seeds collected from three remnant $C$. legalis populations. The first site

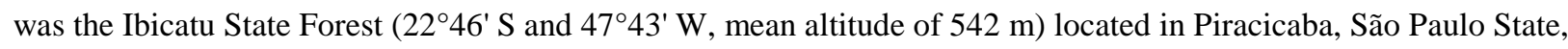
Brazil, which has a total area of 72 ha. The second site was the Mata da Figueira (MGI), a small fragment (7.2 ha) of riparian forest on a semi-deciduous plateau within the Ecological Station Mogi-Guaçu, Farm "Campininha" of the Forestry Institute of São Paulo (22 $16^{\prime} \mathrm{S}$ and $47^{\circ} 11^{\prime} \mathrm{W}$, mean altitude of $\left.600 \mathrm{~m}\right)$. Approximately $2.9 \mathrm{~km}$ from MGI and within the same Ecological Station are four C. legalis trees (MGII). For our analysis, we pooled MGI and MGII, and refer to the combined population as MG. Ibicatu is isolated from other C. legalis populations by at least $2.5 \mathrm{~km}$, while MGI and MGII are $3 \mathrm{~km}$ apart and approximately $75 \mathrm{~km}$ from Ibicatu. We mapped all trees using a GPS III (Garmin, USA) and collected stem bark tissue for microsatellite analysis of all individuals at Ibicatu (65 trees) and MG (26 trees). More than 50 open-pollinated fruit were collected from different parts of the canopy of 15 randomly selected seed trees in Ibicatu, five in MG1 and two in MGII. Sampling was limited at the MG sites, owing to a lack of fruit production in some trees. After harvesting, fruits were packaged in plastic bags separately by seed tree and left in the shade for about 15 days to facilitate DNA seed extraction.

\section{Nursery provenance and progeny test}

In August of 2011, a nursery provenance and progeny trial of C. legalis was established at the University of São Paulo (ESALQ/USP), Piracicaba, São Paulo State, Brazil, using a sub-set of the collected seeds, owing to space limitations. The trial was established in a randomized complete block design at 10 x $10 \mathrm{~cm}$ spacing with 22 families (15 and 7 families from Ibicatu and MG, respectively), five replicates (blocks) and six trees per plot, totalling 30 plants per family (seed tree), and $450\left(n_{I B}\right)$ plants from Ibicatu and $210\left(n_{M G}\right)$ from MG (total in the trial: $n_{T}=660$ plants). The total number of germinated seeds $\left(n_{g}\right)$ in the trial was 553 of 660 (83.8\%), being $378(84.0 \%)$ from Ibicatu and 175 (83.3\%) from MG. Seedlings were evaluated individually for total height (H), root-collar diameter (RCD), and survival (SUR) eight months after germination. Total height and RCD were measured using an IDF Digital Caliper IP67 (IDF Metrology, Pontoglio, Italy) with a resolution of $0.01 \mathrm{~cm}$. The SUR trait presented a binomial distribution as individuals may be living (1) or dead (0), with percentage survival rate calculated as $=\left(n_{\text {survival }} / n_{g}\right) 100 \%$, where $n_{\text {survival }}$ is the number of surviving seedlings. As we could not determine if seeds did not germinate due to inbreeding from selfing or mating among relatives, or from stochastic causes, such as disease and predation, we estimated the realized level of seedling survival from outcrossing among unrelated individuals, related parents and from selfing, based on the genotypes of germinated seedlings from each population (Table 1). 
For all adult trees, DNA was extracted from 100 mg of stem bark tissue per individual using AnalytikJena DNA isolation kits. Seeds were germinated in vermiculite until the cotyledons emerged, and DNA was then extracted from the first true leaf pairs using the method of Doyle and Doyle (1990). Germinated seeds (seedlings) were genotyped for seven microsatellite loci as follows: Ibicatu 600 seeds (from eight fruits of each seed tree, five seeds per fruit, totalling 40 seeds per tree), MGI 250 seeds (50 seeds from ten fruits of each seed tree; five seeds per fruit) and MGII 200 seeds (100 seeds from 20 fruits of each seed tree, five seeds per fruit). We used seven specific microsatellite loci developed for C. legalis (Cle01, Cle04, Cle05, Cle08, Cle09, Cle10, and Cle12), with details on DNA amplification and genotyping for these loci described in Tambarussi et al. (2013a). These microsatellite loci were selected because they exhibited Mendelian inheritance, with high levels of polymorphism and were unlinked (Tambarussi et al. 2013b). The amplification products were separated on a Fragment Analyzer ${ }^{\mathrm{TM}}$ Automated CE System (Advanced Analytical Technologies, Inc. [AATI], Ames, Iowa, USA) using dsDNA Reagent Kit, 35-500 bp. The raw data were analyzed using the software PROSize version 2.0 (AATI). Samples with questionable or missing alleles (peaks), or for which there were mismatches between mothers and progeny, were genotyped a second time.

\section{Paternity analysis}

Paternity analyses were performed using a categorical likelihood method implemented in the Cervus 3.0 program (Marshall et al. 1998; Kalinowski et al. 2007). The power of our seven loci to correctly detect putative pollen donors in the populations was estimated by the non-exclusion probability of a second parent when the first parent is known ( $P_{2}$ ), using Cervus. Paternity analyses for the Ibicatu and MG populations were conducted with the genotypes of adult trees, seed trees and the seeds from each population. To determine putative pollen donors, all adult trees of each population were considered as candidate pollen donors. In the paternity analyses, the most likely pollen donor was determined using the reference allele frequencies from the two adult populations, as suggested by Meagher and Thompson (1987). The paternity of each seed was determined based on the $\Delta$ statistic (Marshall et al. 1998), which is defined as the difference between the "LOD score" of the most likely candidate father and the "LOD score" of the second-most likely candidate. Significance was determined with paternity tests simulated by the Cervus program, with the $\Delta$ statistic determined to a confidence level of $80 \%$, as suggested by Marshall et al. (1998), using 10,000 repetitions. As we did not detect any mismatches between mother and sibs, suggesting no (or very few) genotyping errors, the Cervus default was used for the ratio of genotyping errors (0.01). The proportion of pollen donors sampled was held at $70 \%$, due to the high degree of isolation of the Ibicatu (at least $2.5 \mathrm{~km}$ ) and MG (3 km) populations and the fact that in insect pollinated trees, pollen dispersal generally occurs among near-neighbors, following a pattern of isolation by distance (Dick et al. 2008; Degen and Sebbenn 2014), decreasing the probability of pollen immigration into stands. The minimum number of loci examined to determine the paternity of a seed was fixed at six; thus, one single mismatch among the trio of seed, treeseed and putative pollen donor was accepted. If a seed had no potential pollen donor within the population, that seed 
was considered to have a pollen donor located outside the population (pollen immigration). We estimated the selfing rate ( $S$ ), outcrossing rate $(t)$, outcrossing rate between unrelated parents $\left(t_{u}\right)$ and from related parents $\left(t_{r}\right)$ based on genotypes of the germinated seedlings $\left(n_{g}\right)$. The selfing rate $(S$ ) was estimated as the proportion of seeds determined to have the same seed tree as the pollen donor $\left(n_{s}\right)$ in relation to $n_{g}$ by $s=n_{s} / n_{g}$ and the outcrossing rate was calculated as $t=1-S$. To determine seedlings originating from mating among related parents we estimated the relatedness of seed trees and fathers (assigned by paternity analysis) using the coancestry coefficient ( $\theta$ ) calculated by the method described in Loiselle et al. (1995), and implemented in the Spagedi 1.3 program (Hardy and Vekemans 2002). Following Ismail et al. (2014), if the coancestry between parents ( $\theta$ ) was $\geq 0.1$, we assumed the seedling was inbred due to mating between related parents with $t_{r}=n_{r} / n_{g}$, while mating between unrelated trees was calculated by $t_{u}=n_{u} / n_{g}$, where $n_{u}$ and $n_{r}$ are the number of seedlings that originated from unrelated parents and related parents, respectively. As all sampled adult trees in the populations were genotyped and their spatial position known (x and y coordinates), the seedlings assigned to a pollen donor were used to determine the mean pollen dispersal distance ( $D$ ), and the standard deviation calculated according to the Euclidean distance between the two points. The $95 \%$ confidence interval (95\% CI) was estimated as $=2(S D / \sqrt{n})$, where SD is the standard deviation.

\section{Analyses of genetic diversity and inbreeding}

Genetic diversity and inbreeding were characterized by combining individuals within the populations into three classes: i) outcrossing between unrelated individuals $\left(t_{u}\right)$, ii) mating among related individuals $\left(t_{r}\right)$, and iii) selfing ( $S$ ). The estimated indices were the total number of alleles ( $k$ ), allelic richness $(R)$, and observed heterozygosity $\left(H_{o}\right)$. Inbreeding was estimated by the fixation index ( $F$ ), and significance tested by permuting the alleles among individuals. These analyses were performed using the FSTAT program (Goudet 1995). To investigate if the indices $R$, $H_{o}$ and $F$ were significantly different between seedlings originating from $t_{u}, t_{r}$, and $s$ an unpaired $t$-test (Sokal and Rohlf 1995) was used based on single-locus data.

\section{Inbreeding depression}

Differences in survival and mean growth traits between classes $\left(t_{u}, t_{r}\right.$, and $s$ ) were tested using ANOVA and Tukey procedures in the SAS program (SAS, 1999). Mean inbreeding depression (ID) was estimated for SUR, H and RCD at eight months of age from seedlings in the progeny test, in terms of mating among relatives $\left(I D_{r}\right)$, selfing $\left(I D_{s}\right)$ and the total for mating among relatives and selfing $\left(I D_{T}\right.$ ) according to the following expressions: 
191

192

193

194

$I D_{r}=100 \%\left[1-\left(\bar{x}_{r} / \bar{x}_{u}\right)\right]$,

$I D_{s}=100 \%\left[1-\left(\bar{x}_{s} / \bar{x}_{u}\right)\right]$, and

$I D_{T}=100 \%\left[1-\left(\bar{x}_{i} / \bar{x}_{u}\right)\right]$,

where $\bar{X}_{u}, \bar{X}_{r}, \bar{X}_{s}$ and $\bar{X}_{i}$ are the means of traits for individuals that were from mating between unrelated trees, between relatives, those that were selfed, and all inbred individuals (i.e. selfed + mating among relatives), as determined by paternity analyses and the coancestry coefficient between parents.

\section{Results}

\section{Paternity analysis and mating system}

The non-exclusion probability of a second parent $\left(P_{2}\right)$ across seven microsatellite loci in adults was very low in Ibicatu (0.00215) and MG (0.00045), indicating that this set of loci have good power to detect the pollen donors of seedlings in the populations. The paternity analysis assigned one putative pollen parent for all germinated seedlings (Table 1) and detected one pollen immigrant in MG1, assigned from a MGII tree, indicative of $2 \%$ pollen immigration. Of 378 germinated seedlings from Ibicatu, 20 were assigned to the same seed tree, indicating a realized selfing rate $(S$ ) of 5.3\% (Table 1). In MG, of 175 germinated seedlings, 16 were assigned to the same seed tree, indicating a selfing rate of 9.1\%. Thus, the realized outcrossing rate was $94.7 \%$ and $90.9 \%$ in Ibicatu and MG, respectively. Assuming that seedling parents with coancestry coefficient $\geq 0.1$ are related (95\% CI), the mean pairwise coancestry coefficient ( $\bar{\theta}$ ) among seed trees and assigned unrelated pollen donors was significantly lower [Ibicatu= mean 0.08 (95\% CI 0.07/0.09); $\mathrm{MG}=-0.02(-0.03 /-0.01)]$ than that of the seed trees and assigned related pollen donors that resulted in mating among relatives [Ibicatu= mean $0.22(0.20 / 0.23) ; \mathrm{MG}=0.12(0.11 / 0.14)]$, which suggest that mating among relatives occurred between full-sib parents in Ibicatu $(\theta=0.25)$ and half-sib parents in MG $(\theta=0.125)$. The outcrossing rate among unrelated individuals $\left(t_{u}\right.$ ) was $59.0 \%$ and $46.9 \%$ in Ibicatu and MG, respectively and the mating among relatives rate $\left(t_{r}\right)$ was $35.7 \%$ and $44.0 \%$ in Ibicatu and MG, respectively. Pollen dispersal distances ( $D$ ) were significantly longer for mating resulting in outcrossed seedlings $\left(t_{u}\right)$ than for those produced by mating between relatives $\left(t_{r}\right)$. These results also show that the survival of seedlings originating from $t_{u}$ was higher than from $t_{r}$ and $s$.

\section{Genetic diversity and inbreeding}

Outcrossed seedlings $\left(t_{u}\right)$ of the Ibicatu population exhibited significantly greater mean allelic richness per locus ( $R$ ) and observed heterozygosity ( $H_{o}$ ) than seedlings from mating among relatives $\left(t_{r}\right)$ and selfing $(s$, Table 1$)$. 
Additionally, seedlings that originated from mating among relatives exhibited significantly greater $R$ and $H_{o}$ than selfed seedlings. In the MG population, outcrossed seedlings exhibited significantly greater $R$ than seedlings originating from selfing and significantly greater $H_{o}$ than seedlings from mating among relatives and selfing. Seedlings that originated from mating among relatives showed significantly greater $H_{o}$ than selfed seedlings. In both populations, the fixation index ( $F$ ) was lower for outcrossed seedlings than for seedlings from mating between related individuals and selfed seedlings. The $F$ values were also lower for outcrossed seedlings from related individuals than selfed seedlings. Thus, the genetic diversity indices were always higher and inbreeding lower in seedlings originating from mating among unrelated parents than for seedlings from mating between related individuals or selfing.

\section{Survival and growth rate at 8 months}

Total survival at 8 months after planting of germinated seedlings was high (479 of $553=86.6 \%$ ), being lower in Ibicatu (81.7\%) than in MG (97.1\%) population (Table 2). The ANOVA detected significant differences (F test) among classes $\left(t_{u}, t_{r}\right.$ and $s$ ) for all traits in Ibicatu. Survival of outcrossed seedlings from Ibicatu (93.7\%) was significantly higher than seedlings originating from mating among related individuals (65.2\%) and selfing (60.0\%). Outcrossed seedlings from Ibicatu were significantly taller $(16.5 \mathrm{~cm})$ than those from mating between related individuals $(14.4 \mathrm{~cm})$.

\section{Inbreeding depression}

We observed greater ID in the selfed seedlings in terms of SUR in both populations and H in MG population than in the seedlings produced by mating among relatives, but greater ID in the seedlings produced by mating among relatives than produce from selfing for $\mathrm{H}$ in Ibicatu and RCD in both populations (Table 3). Comparisons of the populations revealed that the total ID in terms of SUR and H was greater in Ibicatu than MG. However, the MG population exhibited the greatest ID in terms of RCD.

\section{Discussion}

To our knowledge this is the second study of ID in a tree species based on results from paternity analyses and estimates of coancestry between seed trees and assigned pollen donors. Ismail et al. (2014) used this method to investigate ID in the tree Viteria indica. In general, ID studies are based on hand pollination, selfing trees or performing matings between individuals with different levels of relatedness and comparing the performance for heritable traits between inbred and non-inbred individuals established in provenance and progeny tests. By contrast, we reconstructed the pedigrees of open-pollinated seeds of $C$. legalis collected in three forest fragments and used a nursery provenance/progeny test to determine which seeds were produced by outcrossing among unrelated trees, selfing and mating between relatives. The 
approach was efficient in showing that ID in C. legalis varied between populations at an early stage of development (8 months of age) in terms of SUR and $\mathrm{H}$.

However, we note that our estimates of mating among relatives may be biased because pairwise relatedness estimates using genetic markers are not straight forward, as some individuals may be related but heterozygous for different alleles at a locus ( $A_{1} A_{2}$ and $\left.A_{3} A_{4}\right)$. Assuming that the frequency of each of four alleles $\left(A_{1}, A_{2}, A_{3}\right.$ and $\left.A_{4}\right)$ in parental (F0) population is 0.25, using Loiselle et al. (1995) method for estimating the coancestry coefficient for pairwise genotypes $A_{1} A_{2}$ and $A_{3} A_{4}$ (F1) with no IBD alleles will result in a coancestry coefficient of -0.33 . Consequently, the pairwise estimate will be biased, in comparison to the expected coancestry between full-sibs (0.25). However, this represents an extreme case for one locus, where related parents (F1) present no IBD alleles in a locus. In other loci, both parents may present the same alleles, producing estimates of pairwise relatedness close to the true relatedness. To discriminate unrelated individuals from half- and full-sibs, requires about 20 polymorphic loci (Blouin et al. 1996).

\section{Realized mating system}

We detected the pollen parent for all seedlings established in the provenance/progeny test. However, as we assigned seedling pollen donors using an $80 \%$ confidence level in the paternity analysis, our results may include some false positive pollen donor assignments (Ismail et al. 2014). At the same confidence level, not all seedlings were assigned in fathers in a pollen flow study based on all seeds sampled from these populations, with 8 and $4 \%$ of pollen flow detected into the Ibicatu and MG populations, respectively (Tambarussi et al. 2015).

We detected higher outcrossing between unrelated individuals in both populations (minimum $t_{u}$ of $47 \%$ ) relative to the crossing rate between relatives (minimum $t_{r}$ of 36\%) and selfing (minimum $S$ of $5 \%$ ), which gave total outcrossing rates $\left(t_{t}=t_{u}+t_{r}\right)$ of $95 \%$ in Ibicatu and $91 \%$ in MG. Thus, the majority of seedlings were produced by outcrossing. These results confirm those of a previous study in three populations of the same species, which revealed that reproduction occurs predominantly by outcrossing, but a portion of mating occurs among related individuals due to intra population spatial genetic structure, with a small amount of selfing (Sebbenn et al. 2000; Tambarussi et al. 2015). However, as our mating system results were estimated using seedlings in a nursery provenance and progeny test, the results represent the realized mating system and probably not that which occurred during fertilization due to the occurrence of ID and the resultant mortality of some inbred individuals between fertilization and the nursery stage. Decreases in outcrossing rates due to ID have been reported for the tropical trees Platypodium elegans (Hufford and Hamrick 2003) and Neobalanocarpus heimii (Naito et al. 2005). Our study detected greater inbreeding due to mating between relatives than from selfing (Table 1). Levels of inbreeding depression varied between seedlings originating from outcrossing among unrelated individuals $\left(t_{r}\right)$ and selfing $(s)$, among traits and among populations. 
Which study trait was most strongly affected by ID?

287

Our results revealed differences between traits in ID levels due to mating among relatives $\left(I D_{r}\right)$ and selfing $\left(I D_{s}\right)$

(Table 3). Generally, SUR showed the greatest ID (ranging from 0.2 to 36\%), and RCD the lowest (ranging from -3.2 to 5.5\%), with the ID for SUR influenced by the trait's binomial distribution (presence or absence) rather than a continuous distribution. Differences in levels of ID between heritable quantitative traits (H and RCD) may be due to dominance and over-dominance effects, with the highest dominance or over-dominance deviations showing the greatest ID (Falconer and Mackay 1997). Variation in ID between traits has also been reported in other tree studies. For example, height, diameter at breast height (dbh) and volume of outcrossed Eucalyptus regnans progeny at 45 months of age were on average 11, 18 and 37\%ef greater, respectively, than values for selfed progeny (Griffin and Cotterill 1988).

\section{Are there differences between populations in ID?}

Inbreeding depression was highest for SUR in the Ibicatu progeny resulting from selfing and mating among relatives, and for $\mathrm{H}$ in the Ibicatu progeny from mating among relatives. The MG population exhibited the greatest ID due to selfing in terms of $\mathrm{H}$ and in RCD due to mating between relatives. The greater ID in Ibicatu was probably due to a higher frequency of deleterious alleles or genetic load. For example, Karkkainen et al. (1996) studied geographic variation in ID of Pinus sylvestris and observed variation between regions in the mean rate of seed abortion and the number of lethal embryos among progeny derived from selfing, suggesting that different populations may have different genetic load levels.

\section{What is the difference in ID between individuals originating from selfing and mating among relatives?}

The effects of ID due to selfing and mating among relatives were variable across the studied traits with differences between H and RCD compared to SUR partly due to the first two being continuous variables, whereas SUR presents a binomial distribution. For SUR, ID was greater among selfed seedlings $\left(I D_{s}\right)$ than in seedlings originating from mating between related individuals ( $I D_{r}$ ). By contrast, for $\mathrm{H}$ and RCD, selfed individuals exhibited lower ID than those resulting from mating between relatives, with the exception of $\mathrm{H}$ in the MG population, which showed the opposite pattern. Selfing produced the minimum of 50\% homozygosity for IBD alleles in heterozygous loci of the seed trees, and mating between relatives produced inbreeding equal to the coancestry among the parents. Thus, selfing is expected to produce greater ID than mating between related individuals, as was observed for SUR in both populations and $\mathrm{H}$ in the MG population. The contrasting results for $\mathrm{H}$ in the Ibicatu population and RCD in both populations can be linked to the greater ID observed for SUR. As SUR was lower among the selfed seedlings than those resulting from mating between relatives, it is probable that only selfed individuals with low genetic loads, and consequently low ID due to 
selfing, survived to be measured for $\mathrm{H}$ and RCD eight months after germination. Thus, ID for these traits was higher among seedlings resulting from mating between relatives, possibly because these seedlings exhibited greater survival than those originating from selfing, due to the low combination likelihood of homozygous IBD alleles. Furthermore, some embryo mortality may occur before germination, and our estimate represents a rate of realized selfing and mating among relatives, not the rate at fertilization. However, our results do represent an early effect of ID. Inbreeding depression may act at various stages of seedling development, and it is possible that ID that results from both selfing and mating among relatives will continue to act on these traits. For example, Sorensen and Miles (1982) found that ID for survival in Pseudotsuga menziesii, Pinus ponderosa and Abies procera, was greatest within the first two years of planting (range of 3 to $16 \%$ ), whereas these values were 0.4 to $3 \%$ ten years after planting.

\section{Are there differences in genetic diversity between seeds produced by selfing, mating between relatives and} outcrossing?

Our results revealed clear associations of mating system indices $\left(t_{u}, t_{r}\right.$ and $\left.s\right)$, survival, allelic richness $(R)$, observed heterozygosity ( $H_{o}$ ) and fixation index $(F)$. Generally, in both populations, the greater survival of seedlings resulting from outcrossing among unrelated individuals gave greater $R$ and $H_{o}$ and lower $F$ compared to seedlings from mating among related trees, and from selfing. As expected, we also detected that seedlings from mating between relatives exhibited significantly higher $R$ and $H_{o}$ and lower $F$ than those from selfing (Table 1). As already mentioned, selfing and mating between relatives result in increases in homozygosity in IBD deleterious alleles, and decreases in genetic diversity relative to outcrossing between unrelated trees. Furthermore, selfing increases IBD to a level greater than that resulting from mating between relatives, as only maternal IBD alleles are present in selfed individuals.

\section{What are the expected levels of ID in offspring generations based on random seedling samples from these}

\section{populations?}

The probabilities of observing ID in seedlings from Ibicatu ( $I D_{T}$ ) were higher than in the MG seedlings for SUR, with the reverse pattern for RCD. Rates of selfing and mating between relatives, inbreeding (estimated from the fixation index), and mean homozygosis for seedlings originating from selfing were lower in Ibicatu than in MG, leading to the expectation that ID would be greater in the MG population. As this expectation was not met, a lower genetic load is the probable explanation due to different frequencies of deleterious alleles for these traits in each population.. As such it is likely that other fragmented populations of $C$. legalis will also show ID, but may well vary in ID levels for different variables. 
This study shows the effectiveness of combining paternity analysis and relatedness estimates with a progeny trial for studying ID, as part of a broader study on gene flow and mating system, and without the complication and cost of conducting controlled pollinations. The approach is likely to be most effective in tree species without a selfincompatibility mechanism, where human disturbance (e.g. fragmentation, logging) produces sufficiently large increases in inbreeding (selfing and mating among related individuals) to produce adequate numbers of inbred seedlings to compare in field trials. Our results show the importance of studying ID over a number of populations and traits, while it is also necessary to study a population over many years to understand the temporal dynamics of ID.

\section{Implications}

The detected levels of ID from selfing and mating between related individuals in C. legalis populations have practical implications for genetic conservation, breeding and environmental restoration in terms of their impacts on survival and growth. The collection of open-pollinated seed from trees in fragmented populations is common practice and it is impossible to stop inbreeding in open-pollinated seeds as the species is self-compatible and intra-population spatial genetic structure also leads to some bi-parental inbreeding (Tambarussi et al. 2015). However, the following measures can be applied to minimize the use and establishment of inbred seedlings and ensure genetic diversity in ex situ genetic conservation, breeding and environmental restoration. 1) Keep seedlings identified by mother tree in the nursery - it will become evident which families show higher mortality and thus higher levels of inbreeding. This will also allow equal numbers of seedlings from each seed tree to be used in planting, ensuring both genetic balance and diversity. 2) In the nursery, eliminate seedlings with indications of inbreeding i.e. those with diseases, chlorosis, stunted growth or other abnormalities. This will ensure that survival and growth in the field will not be greatly constrained by inbreeding impacts. 3) Collect from a large number of mother trees across a range of fragments - this will ensure that sufficient genetic diversity is maintained even while eliminating inbred material. These strategies decrease the likelihood of inbred seedlings becoming established in ex situ gene banks, breeding programmes and at restoration sites, thus ensuring that the fitness of established seedling populations is higher than that of the seed population and increasing the evolutionary adaptive potential of such programmes.

\section{Acknowledgements}

We thank the Fundação de Amparo à Pesquisa do Estado de São Paulo (FAPESP - 2010/10704-7) and Conselho Nacional de Desenvolvimento Científico e Tecnológico (CNPq - 470491/2010-8) for funding this project. Evandro V. Tambarussi was supported by a FAPESP PhD scholarship (grant 2010/12354-3). Alexandre M. Sebbenn, Miguel L.M. Freitas and Roland Vencovsky are supported by CNPq research fellowships. We thank Tiago Gabassi for help in the laboratory and Wladimir Correa and Dirceu de Souza for their help in collecting the plant samples. We also thank NPGLE for corrections to the English. 


\section{References}

Bittencourt JM, Sebbenn AM (2007) Patterns of pollen and seed dispersal in a small fragmented population of a wind pollinated Araucaria angustifolia in southern Brazil. Heredity 99: 580-591.

Blouin MS, Parsons M, Lacaille V, Lotz S (1996) Use of microsatellite loci to classify individuals by relatedness. Mol Ecol 5: 393-401.

Byers DL, Waller DM (1999) Do plant populations purge their genetic load? Effects of population size and mating history on inbreeding depression. Annual Review of Ecology and Systematics 30: 479-513.

Carvalho PER (2003) Espécies arbóreas brasileiras. Brasília: Embrapa Informação Tecnológica.

Charlesworth D, Charlesworth B (1987) Inbreeding depression and its evolutionary consequences. Ann Rev Ecol Syst 18: $237-268$.

Chaves LJ, Vencovsky R, Silva RSM, Telles MPC, Zucchi MI, Coelho ASG (2011) Estimating inbreeding depression in natural plant populations using quantitative and molecular data. Conserv Genet 12: 569-576.

Degen B, Sebbenn AM (2014) Genetics and tropical forests. In: Pancel L, Kölh M (eds) Tropical Forestry Handbook, 2nd edn. Springer, Berlin, pp 885-920.

Dick CW, Hardy OJ, Jones FA, Petit RJ (2008) Spatial scales of pollen and seed-mediated gene flow in tropical rain forest trees. Tropical Plant Biol 1: 20-33.

Doyle JJ, Doyle JL (1990) Isolation of plant DNA from fresh tissue. Focus 12: 13-15.

Falconer DS, Mackay TFC (1997) Introduction to Quantitative Genetics. Longman Group Ltd, England.

Goudet J (1995) Fstat (Version 2.9.3.2.): A computer program to calculate F-statistics. J Hered 86: 485-486.

Griffin AR, Cotterill PP (1988) Genetic variation in growth of outcrossed, selfed and open-pollinated progenies of Eucalyptus regnans end some implications for breeding strategy. Silvae Genet 37: 124-131.

Hardy O, Vekemans X (2002) SPAGeDI: a versatile computer program to analyze spatial genetic structure at the individual or population levels. Mol Ecol Notes 2: 618-620.

Hufford KM, Hamrick JL (2003) Viability selection at three early life stages of the tropical tree, Platypodium elegans (Fabaceae, Papilionoideae). Evolution 57: 518-526.

Ismail SA, Ghazoul J, Ravikanth G, Uma Shaanker R, Kushalappa CG, Kettle CJ (2012) Does long-distance pollen dispersal preclude inbreeding in tropical trees? Fragmentation genetics of Dysoxylum malabaricum in an agroforest landscape. Mol Ecol 21: 5484-5496.

Ismail SA, Ghazoul J, Ravikanth G, Uma Shaanker R, Kushalappa CG, Kettle CJ (2014) Fragmentation genetics of Vateria indica: implications for management of forest genetic resources of an endemic dipterocarp. Conserv Genet 15: 533-545. 
Kalinowski ST, Taper ML, Marshall TC (2007) Revising how the computer program CERVUS accommodates genotyping error increases success in paternity assignment. Mol Ecol 16: 1099-1106.

Kärkkäinen K, Savolainen O (1996) The degree of early inbreeding depression determines the selfing rate at the seed stage: Model and results from Pinus sylvestris (Scots pine). Heredity 71: 160-166.

Koelewijn HP, Koski V, Savolainen O (1999) Magnitude and timing of inbreeding depression in Scots Pine (Pinus sylvestris L.). Evolution 53: 758-768.

Lindgren D, Luigi DG, Jefferson PA (1997) Status number for measuring genetic diversity. Forest Genet 4: 69-76.

Loiselle BA, Sork VL, Nason J, Graham C (1995) Spatial genetic structure of a tropical understory shrub, Psychotria officinalis (Rubiaceae). Am J Bot 82: 1420-1425.

Lowe AJ, Boshier D, Ward M, Bacles CFE, Navarro C (2005) Genetic resource impacts of habitat loss and degradation; reconciling empirical evidence and predicted theory for neotropical trees. Heredity 95: 255-273.

Manoel RO, Alves PF, Dourado CL, Gaino APSC, Freitas MLM, Moraes MLT, Sebbenn AM (2012) Contemporary pollen flow, mating patterns and effective population size inferred from paternity analysis in a small fragmented population of the Neotropical tree Copaifera langsdorffii Desf. (Leguminosae-Caesalpinioideae). Conserv Genet 13: 613-623.

Marshall TC, Slate J, Kruuk LEB, Pemberton JM (1998) Statistical confidence for likelihood-based paternity inference in natural populations. Mol Ecol 7: 639-655.

Meagher TR, Thompson E (1987) Analysis of parentage for naturally established seedlings of Chamaelirium luteum (Liliaceae). Ecology 68: 803-812.

Naito Y, Konuma A, Iwata YS, Seiwa K, Okuda T, Lee SL, Muhammad N, Tsumura Y (2005) Selfing and inbreeding depression in seeds and seedlings of Neobalanocarpus heimii (Dipterocarpaceae). J Plant Res 118: 423-430.

Prance GT, Mori SA (1979) Lecythidaceae - Part 1. Flora Neotropica Monograph. 21: 1-272.

Ritland K (1996) Inferring the genetic basis of inbreeding depression in plants. Genome 39: 1-8.

Rymer PD, Sandiford M, Harris SA, Billingham MR, Boshier DH (2015) Remnant Pachira quinata pasture trees have greater opportunities to self and suffer reduced reproductive success due to inbreeding depression. Heredity 115 : 115-124.

Sebbenn AM, Kageyama PY, Siqueira ACMF, Zanatto ACS (2000) Sistema de cruzamento em populações de Cariniana legalis Mar. O. Ktze.: implicações para a conservação e o melhoramento genético. Sci For 58: 24-40. SAS (1999) Institute Inc. SAS procedures guide. Version 8 (TSMO). SAS, Cary.

Sokal RR, Rohlf FJ (1995) Biometry: principles and practices of statistics in biological research. Third Edition. W.H. Freeman and Company, New York.

Sorensen FC, Miles R (1982) Inbreeding depression in height, height growth and survival of Douglas-Fr, Ponderosa Pine, and Noble Fir to 10 years of age. For Sci 28: 283-292. 
Tambarussi EV, Sebbenn AM, Moreno MA, Ferraz EM, Kageyama PY, Vencovsky R (2013a) Microsatellite markers for Cariniana legalis (Lecythidaceae) and their transferability to Cariniana estrellensis. Appl Plant Sci 1: 1200493.

Tambarussi EV, Vencovsky R, Freitas MLM, Sebbenn AM (2013b) Mendelian inheritance, genetic linkage and genotypic disequilibrium at nine microsatellite loci of Cariniana legalis (Mart.) O. Kuntze. Genet Mol Res 12: 5442-5457.

Tambarussi EV, Boshier DH, Vencovsky R, Freitas MLM, Di-Dio O-J, Ferraz EM, Moreno MA, Sebbenn AM (2015) Paternity analysis reveals significant isolation and near neighbour pollen dispersal in small Cariniana legalis Mart. Kuntze populations in the Brazilian Atlantic Forest. Ecology and Evolution 5: 5588-5600.

Winn AA, Elle E, Kalisz S, Cheptou PO, Eckert CG, Goodwillie C, Johnston MO, Moeller DA, Ree RH, Sargent RD, Vallejo-Marín M (2011) Analysis of inbreeding depression in mixed-mating plants provides evidence for selective interference and stable mixed mating. Evolution 65: 3339-3359.

Wu HX, Matheson AC, Spencer D (1998) Inbreeding in Pinus radiata. 1. The effect of inbreeding on growth, survival and variance. Theor Appl Genet 97: 1256-1268. 
Table 1 Results of the mating system, mean coancestry coefficient, pollen dispersal distance between parents, genetic diversity and inbreeding of the Ibicatu and Mogi-Guaçu (MG) populations of Cariniana legalis. $t_{u}, t_{r}$ and $s$ are the rate of outcrossing among unrelated individuals, outcrossing among related individuals, and selfing, respectively; $n_{g}$ and $n_{a}$ are the number of germinated and assigned seedlings for pollen donors, respectively; $95 \%$ CI is the $95 \%$ confidence interval; min-max is the minimum and maximum values. The different letters indicate significant differences at the $5 \%$ level by the unpaired t-test; $* P<0.05$.

\begin{tabular}{|c|c|c|c|}
\hline & $t_{u}$ & $t_{r}$ & $S$ \\
\hline \multicolumn{4}{|l|}{ Ibicatu: $n_{g}=378$} \\
\hline Assigned: $\left.\left.n_{a}\left[n_{a} / n_{g}\right) 100 \%\right)\right]$ & $223[59.0 \%]$ & $135[35.7 \%]$ & $20[5.3 \%]$ \\
\hline Coancestry between parents: $\bar{\theta}$ (95\% CI) & $0.08(0.07 / 0.09)^{*}$ & $0.22(0.20 / 0.23)^{*}$ & - \\
\hline Distance between parents: $D(\mathrm{~m})(\min / \max )$ & $378(322 / 434)$ & $268(176 / 360)$ & - \\
\hline Total number of alleles: $k$ & 99 & 80 & 50 \\
\hline Allelic richness for five individuals: $R$ & $6.1 \mathrm{~A}$ & $5.3 \mathrm{~B}$ & $4.3 \mathrm{C}$ \\
\hline Observed heterozygosity: $H_{o}$ & $0.85 \mathrm{~A}$ & $0.76 \mathrm{~B}$ & $0.52 \mathrm{C}$ \\
\hline Fixation index: $F$ & $0.02 \mathrm{~A}$ & $0.06 A^{*}$ & $0.26 B^{*}$ \\
\hline \multicolumn{4}{|l|}{ Mogi-Guaçu: $n_{g}=175$} \\
\hline Assigned: $\left.n_{a}\left[n_{a} / n_{g}\right) 100 \%\right]$ & $82[46.9 \%]$ & $77[44.0 \%]$ & $16[9.1 \%]$ \\
\hline Coancestry between parents: $\bar{\theta}(95 \% \mathrm{CI})$ & $-0.02(-0.03 /-0.01)^{*}$ & $0.12(0.12 / 0.14)^{*}$ & - \\
\hline Distance between parents: $D(\mathrm{~m})(\min / \max )$ & $144(1 / 288)$ & $28(12 / 44)$ & - \\
\hline Total number of alleles: $k$ & 83 & 86 & 38 \\
\hline Allelic richness for five individuals: $R$ & $5.8 \mathrm{~A}$ & $5.8 \mathrm{~A}$ & $4.4 \mathrm{~B}$ \\
\hline Observed heterozygosity: $H_{o}$ & $0.91 \mathrm{~A}$ & $0.73 \mathrm{~B}$ & $0.34 \mathrm{C}$ \\
\hline Fixation index: $F$ & $-0.08 A^{*}$ & $0.14 \mathrm{~B}^{*}$ & $0.58 C^{*}$ \\
\hline
\end{tabular}


Table 2 Survival (SUR), total height (H) and root-collar diameter (RCD) at 8 months of the Ibicatu and Mogi-Guaçu

\begin{tabular}{lccccc}
\hline & $n_{g}$ & $n_{\text {survival }}$ & SUR $(\%)$ & $\mathrm{H}(\mathrm{cm})$ & $\mathrm{RCD}(\mathrm{cm})$ \\
\hline Ibicatu & 223 & 209 & $93.7 \mathrm{~A}$ & $16.49 \mathrm{~A}$ & $3.17 \mathrm{~A}$ \\
Assigned for $t_{u}$ & 135 & 88 & $65.2 \mathrm{~B}$ & $14.40 \mathrm{~B}$ & $3.09 \mathrm{~A}$ \\
Assigned for $t_{r}$ & 20 & 12 & $60.0 \mathrm{~B}$ & $16.46 \mathrm{~A}$ & $3.28 \mathrm{~A}$ \\
Assigned for $s$ & & & 81.7 & 15.93 & 3.15 \\
Mean & & & 0.001 & 0.004 & 0.001 \\
$P_{\text {value }}$ & 155 & 100 & 65.0 & 14.76 & 3.11 \\
Assigned for $t_{r}+s$ & 378 & 309 & & & \\
Total & 82 & 80 & $97.6 \mathrm{~A}$ & $10.76 \mathrm{~A}$ & $2.30 \mathrm{~A}$ \\
\hline MG & 77 & 75 & $97.4 \mathrm{~A}$ & $10.66 \mathrm{~A}$ & $2.18 \mathrm{~A}$ \\
Assigned for $t_{u}$ & 16 & 15 & $93.7 \mathrm{~A}$ & $10.41 \mathrm{~A}$ & $2.38 \mathrm{~A}$ \\
Assigned for $t_{r}$ & & & 97.1 & 10.69 & 2.25 \\
Assigned for $s$ & & & 0.438 & 0.886 & 0.697 \\
Mean & & & 96.8 & 10.62 & 2.21 \\
$P_{\text {value }}$ & 93 & 90 & & & \\
Assigned for $t_{r}+s$ & 175 & 170 & & & \\
Total & & & & & \\
\hline
\end{tabular}

(MG) populations of Cariniana legalis. $t_{u}, t_{r}$ and $s$ are the rate of outcrossing among unrelated individuals,

s).

outcrossing among related individuals, and selfing, respectively; $n_{a}$ and $n_{\text {survival }}$ are the number of germinated seedling and survival seedlings at 8 moths, respectively. The different letters indicate significant differences at the $5 \%$ level by

Tukey test. $P_{\text {value }}$ is the probability of F value of the ANOVA be significant among trait for groups $\left(t_{u}, t_{r}\right.$ and 
481 Table 3 Inbreeding depression (ID) in percent (\%) due to mating between relatives ( $I D_{r}$ ), selfing ( $I D_{s}$ ) and total $482\left(I D_{T}\right)$ for survival (SUR), height (H), and root-collar diameter (RCD) in the Ibicatu and Mogi-Guaçu (MG) populations 483 of Cariniana legalis.

\begin{tabular}{|c|c|c|c|c|c|c|}
\hline & \multicolumn{3}{|c|}{ Ibicatu } & \multicolumn{3}{|c|}{ MG } \\
\hline & SUR & $\mathrm{H}$ & RCD & SUR & $\mathrm{H}$ & RCD \\
\hline ID due to mating between relatives: $I D_{r}$ & $30.4 \%$ & $12.8 \%$ & $3.9 \%$ & $0.2 \%$ & $1.0 \%$ & $5.5 \%$ \\
\hline ID due to selfing: $I D_{s}$ & $36.0 \%$ & $0.0 \%$ & $-3.2 \%$ & $3.9 \%$ & $3.3 \%$ & $-3.2 \%$ \\
\hline Total ID: $I D_{T}$ & $31.2 \%$ & $11.5 \%$ & $3.1 \%$ & $0.8 \%$ & $1.3 \%$ & $4.1 \%$ \\
\hline
\end{tabular}

